\title{
CAROLINA E O DRAMA DA POPULAÇÃO DESCARTÁVEL
}

\author{
Rita de Cássia Camargor \\ ritafaizah@bol.com.br \\ Lourenço Cardoso \\ lourencocardoso@uol.com.br
}

Resumo: Neste breve ensaio foi possível constatar, entre outras coisas, que o cânone literário brasileiro não é neutro. Ao contrário, é localizado, ou seja, hegemonicamente branco, ocidental e paternalista. No que se refere à escritora $\mathrm{Ca}-$ rolina Maria de Jesus, ao falar por si mesma, acaba por provocar tensão, situação que torna difícil ser indiferente a sua figura e literatura. Se é difícil tratá-la com indiferença, a melhor estratégia é invisibilizá-la. O Núcleo História e Memória do Museu AfroBrasil, ao visibilizar Carolina Maria de Jesus, possilibilita às pessoas conhecerem-na e, desta maneira, resgata uma parte de nossa História.

Palavras-chave: Colonização; Invisibilidade; Literatura; Miséria

\section{0 . INTRODUÇÃo}

O Núcleo História e Memória do Museu AfroBrasil é uma proposta do artista plástico e curador Emanuel Araújo, em conjunto com o literato

I Pesquisadora, mestranda do Programa de Estudos Interdisciplinares sobre Mulheres, Gênero e Feminismo pela ufba, (Brasil), Bacharel em Letras pela Puc-sp, (Brasil).

2 Pesquisador, doutorando em Sociologia pela Unesp/Araraquara (Brasil), mestre em Sociologia pela Universidade de Coimbra (Portugal), bacharel em História pela PUcsP (Brasil). 
Oswaldo de Camargo, com a intenção de reavivar a memória da população brasileira quanto às personalidades negras que contribuíram com um novo olhar para a Literatura, a Medicina, a Arquitetura, a Política, a Música e o Teatro. O espaço busca, por meio de imagens, representar o trabalho de intelectuais que atuam em distintos campos do conhecimento por meio de uma linha do tempo que vai desde o século xviII até o xxi. Destacando um dado importante, tal como a atuação de intelectuais negros no século XviII no campo da Medicina, Arquitetura, Engenharia, Literatura, dentre outros, já no século xx este campo se restringe apenas às artes, como a música, o teatro e os desportos.

Entre as personalidades homenageadas, temos a autora brasileira Carolina Maria de Jesus, nascida na cidade de Sacramento (MG) em I9I4. A autora, com uma visão perspicaz, traz em sua produção literária faces do nosso país. Carolina de Jesus ficou conhecida pelo livro Quarto de despejo, narrativa autobiográfica que aborda um cotidiano não muito comum à literatura brasileira, ou seja, retrata a miséria da favela do Canindé. Sua publicação neste ano completa 50 anos, narrativa esta que fez com que a escritora ficasse conhecida no Brasil e em outros países, tais como a França, os Estados Unidos e o Japão.

Porém, apesar de toda projeção na época, Carolina de Jesus ainda é pouco conhecida e reconhecida na sociedade brasileira nos dias atuais. A visibilidade dada a Quarto de Despejo foi determinante para a invisibilidade a sua produção nos anos posteriores, isto é, a projeção da escritora veiculada pela mídia, desenhando-a como uma figura exótica, uma escritora negra favelada, pode ter interferido para o desconhecimento de sua obra posteriormente, contribuindo, portanto, para a invisibilização de sua produção literária.

No decorrer destes seis anos de existência, o Museu AfroBrasil busca difundir esta produção literária afro-brasileira que ainda permanece invisibilizada no cenário nacional. No mês de maio de 20II, a biblioteca que compõe o acervo do museu Afro Brasil prestou uma homenagem a Caro- 
lina Maria de Jesus. Além de a biblioteca receber seu nome, foi realizado um evento que reuniu Vera Eunice, filha de Carolina de Jesus, Audálio Dantas, jornalista que foi responsável pela publicação do livro Quarto de Despejo, Oswaldo de Camargo, escritor, e Jaqueline Romio, pesquisadora. O evento foi mediado por Ligia Ferreira Fonseca, professora da Universidade Federal de São Paulo (Unifesp).

O intuito do encontro, intitulado Viva Carolina Viva, foi debater as formas de difusão da produção literária de Carolina Maria de Jesus no país. O mais surpreendente neste seminário foi a resposta do jornalista Audálio Dantas, referente à possibilidade de disponilibilizar ao público as produções de Carolina que estão sob sua guarda. O jornalista respondeu que não as disponibilizaria porque simplesmente não era de sua vontade. Diante dessa afirmação, Vera Eunice, filha de Carolina, expôs de maneira tímida sua indignação quanto à postura do jornalista.

Vale ressaltar que, no Brasil, esse jornalista é uma das grandes referências quando se menciona a produção de Carolina de Jesus. Ele próprio, em alguns momentos de sua palestra, trouxe à tona o fato de ter sido o principal responsável por transformar o diário de Carolina em livro. Destacou ainda, na ocasião, que descobrir essa autora foi um "furo de reportagem", que se tornou um dos trabalhos mais importantes de sua carreira.

Quanto ao Núcleo História e Memória do Museu AfroBrasil trata-se de um espaço que proporciona ao público a oportunidade de conhecer a obra de Carolina Maria de Jesus e outras personalidades negras. Dir-se-ia, por outras palavras, que o Núcleo História e Memória contribui para visibilização da produção literária afro-brasileira, ao mesmo tempo em que estimula o olhar crítico ao nosso cânone literário. Esse estímulo ao questionamento do cânone não se restringe somente ao campo literário, mas também a uma reflexão da própria produção científica brasileira. Numa escala maior, trata-se de uma apreciação crítica da ótica hegemônica da produção científica no Brasil, teorias que revelam uma ótica ocidental, eurocêntrica, paternalista, heterossexual do mundo. 
Portanto, não se trata de uma produção científica neutra e universal (Haraway, I995:7-4I). Ao contrário, é situada e nessas produções geralmente o pesquisador ou o literato pertence ao grupo opressor e/ou ex-colonizador. Chamam a atenção os estudos pós-coloniais que indicam que o oprimido (e/ou ex-colonizado) também possui a capacidade intelectual de falar a respeito da opressão, que o "subalternizado" pode falar por si mesmo.

Carolina Maria de Jesus se enquadra nesse perfil. Além falar por si mesma, do lugar da opressão, ela produz literatura a partir desse mesmo lugar de enunciação, razões pelas quais, talvez, isso resultou na sua invisibilização no cânone literário.

Os estudos pós-coloniais possuem forte tradição anglo-saxônica a partir dos anos 1970. No entanto, partimos da hipótese de que podemos aproximar e inclusive situar a obra de Carolina de Jesus na linha desses estudos pós-coloniais, devido às questões de que ela trata. Podemos encontrar, com efeito, outros literatos e teóricos brasileiros que poderíamos aproximar dos que são classificados como autores pós-coloniais em nosso território (Araújo, 2010: 22I-242).

\section{Estudos pós-coloniais e Carolina de Jesus}

Considera-se o livro Orientalismo, de Edward Said, o marco de fundação da ótica pós-colonial. Essa perspectiva teria começado a ser esboçada por Frantz Fanon ao procurar descrever a modernidade do ponto de vista do negro e do colonizado (Costa, 2006: 85). Historicamente, a teoria pós-colonial surge como crítica literária na Inglaterra a partir da hegemonia da língua inglesa e das estratégias políticas de colonização do Império Britânico. No entanto, a obra mais marcante dessa linha teórica é, de fato, o Orientalismo de Said, marco de uma tendência de estudos que se fortalece atualmente com a produção de Gayatri Spivak, Homi Bhabha entre outros (Said, 2004, Bahbha, 2003). Vale ressaltar que a perspectiva 
marcadamente culturalista dessa linha de estudos pode levar ao ocultamento da materialidade das relações históricas, sociais e políticas. $\mathrm{O}$ pós-colonialismo surge e se fortalece como uma teoria que constata as marcas da colonização.

No campo das ciências sociais, o pós-colonialismo tenta impor-se como uma teoria crítica que identifica o processo de descolonização enquanto acontecimento que não findou com o fim da colonização. O colonialismo transformou-se, ficando arraigado nos alicerces das sociedades pós-coloniais. O racismo seria uma herança do período colonial que se sustenta em nossa sociedade moderna, assim como aponta Paul Gilroy em Atlântico Negro (Gilroy, 20or: 33-100). Para os sociólogos, a economia é também um indicador de domínio e subjugação. Provavelmente os estudos pós-coloniais podem vir a enriquecer os estudos sociológicos, a epistemologia da sociedade moderna, que hierarquiza os conhecimentos, desvalorizando as produções não ocidentais.

A teoria pós-colonial é constituída por uma matriz de autores e pesquisadores indianos, africanos, palestinos, caribenhos, ingleses, portugueses e latino-americanos, e, entre estes, argentinos, uruguaios, bolivianos e brasileiros, apesar de a maioria não optar por este conceito devido à distância histórica de nosso passado colonial. (Araújo, 20Io: 22I-242). Como foi mencionado, o ponto de vista predominante da teoria pós-colonial é literária e classifica, geralmente, como literatura pós-colonial, a produção dos autores dos povos colonizados pelos europeus entre os séculos $\mathrm{xV}$ e xx. Trata-se de uma literatura resultante da experiência de colonização ou da imaginação dessa experiência. A crítica pós-colonial pode ser entendida como uma abordagem alternativa que procura analisar o colonialismo e seus impactos como fenômeno local e global (Bonnici, r998: 7-23). No entanto, é importante lembrar que as sociedades pós-coloniais não são iguais: existem pós-colonialismos. Stuart Hall lembra-nos que o "pós" do "pós-colonial" não deve ser reduzido a uma simples periodização (Hall, 2003:IOI-I23). 
Diante de tudo isso que foi mencionado, estamos convencidos sobre dois pontos, ou melhor, duas hipóteses: (a) No cenário brasileiro existe a possibilidade de utilizarmos como arcabouço teórico os estudos pós-coloniais e (b) A obra literária de Carolina de Jesus se enquadra no perfil que consideramos como literatura pós-colonial brasileira. Existe um provérbio africano muito antigo que diz: "Também o leão deverá ter quem conte a sua história. As histórias não podem glorificar apenas o caçador". Essa frase é muito empregada pela linha dos estudos pós-coloniais, nela se achando subentendida a idéia de que, mais importante do que alguém contar a história do "vencido", seria que o "vencido" contasse a sua própria história. Carolina Maria de Jesus encontra-se nesse lugar. A literata a partir do seu lugar de enunciação, ou seja, em sua condição de mulher, negra e pobre, passa a contar sua memória individual que é, também, ao mesmo tempo, nossa história coletiva.

Definitivamente pensamos que é, de fato, necessário o "subalternizado" contar sua versão da história. De repente o "oprimido", ou "marginalizado", ao falar por si mesmo, não se reconhece como "vencido", ou melhor, talvez, nos diga que a história de vencedor e vencido é uma construção colonial e imperialista, fruto de uma pessoa ou grupo violento. Logo, a obra de Carolina Maria de Jesus propõe, mais que o "óbvio direito de falar”, que tanto propugnam os autores pós-coloniais estrangeiros, o não reconhecimento da subalternação. Ao nos propor agir dessa maneira, faz com que não seja satisfeita a carência do suposto "vencedor", mesmo diante de toda força expressa em sua máquina de guerra e outras formas de violências rudimentares.

\section{A descolonização da literatura braSiLEIRA}

$\mathrm{Na}$ literatura brasileira vigora a brancura ${ }^{3}$, ou seja, autores brancos, estética branca, soma-se a hierarquia racial à predominância masculina (Car-

3 Cf. Cardoso, 2008. 
doso, 2008: 82-84). As preocupações do homem branco é o grande tema abordado, ele que possui a mulher, a criança e o negro, aquilo que se costuma chamar popularmente de "fardo do homem branco". De maneira geral, no cânone literário a mulher negra e o homem negro encontram-se marginalizados, ignorados ou invisibilizados (Sovik, 2005, I59-I80). Esse aspecto é saliente porque contrasta com a realidade brasileira, onde encontramos homens e mulheres negras em cada esquina. Sem ignorar o fato de que, nos espaços de maior prestígio e poder simbólico e econômico, os negros ainda são minoria, aspecto explicado pela teoria social brasileira como resultante do racismo, preconceito e discriminação racial (Hasenbalg, 2005: 207-23I). Tal fenômeno social é também apontado na literatura e nos depoimentos de Carolina Maria de Jesus.

No caso da literatura negra brasileira, convém ressaltar um aspecto importante. Referimo-nos a uma produção artística de autoria de negras e de negros. Os escritores de maneira geral encontram-se na hierarquia social como os intelectuais de maior prestígio e glamour social, em escala que extrapola o contexto local. A título ilustrativo, podemos citar o português José Saramago, os brasileiros Jorge Amado e Cecília Meireles, o italiano Dário Fo, o argentino Jorge Luís Borges, entre outros.

No imaginário social, o escritor é considerado pensador e criador. Talvez sejam essas duas características atribuídas ao escritor que fazem com que se recuse o reconhecimento aos escritores e escritoras negras ou, vale a pena sublinhar, a capacidade humana de criar e de pensar (Fanon, 1952), atributos que Carolina Maria de Jesus esbanja de forma elegante, levando a mentalidade racista a contrariar, a contestar, ou a reconhecê-la de forma subalterna, promovendo uma forma de "inclusão excludente". Isso significa que Carolina não é considerada uma escritora, e sim, uma escritora negra. Neste caso, o termo negro possui a função de colocá-la numa posição hierárquica inferior ao escritor branco (Cleaver, I971: 152I53, Santos, 2006: 259-293). 
Nessa mesma lógica de raciocínio, Carolina é classificada como escritora "favelada", isto é, produto exótico que deve ser consumido em virtude dos aspectos excepcionais que representa: suas características, enquanto mulher negra de meia idade, catadora de papel, com pouca escolaridade, mulher que ousa pensar e produzir literatura sobre sua vida pessoal. Para sermos mais específicos, Carolina Maria de Jesus foi uma pessoa que estudou até a segunda série do curso primário, numa cidade pequena do interior de Minas Gerais. Trabalhou como lavradora, migrou para São Paulo, exerceu função de empregada doméstica, manteve-se na maior parte do tempo como catadora de papel, ferros e estopa no lixo, além, de ser mãe solteira de três filhos pequenos. Sua história pessoal difícil não impediu que alcançasse um extraordinário êxito num breve espaço de tempo, de proporção tamanha que muitas outras pessoas não alcançam numa vida inteira. Sua expressão artística não diz respeito somente ao conflito individual, mas se refere, igualmente, ao nosso drama humano.

Numa breve comparação, a literatura de Carolina Maria de Jesus trata de temas sociais, assim como Vidas Secas de Graciliano Ramos ou $O$ Quinze, de Rachel de Queiroz. Todavia, a literatura de Carolina de Jesus refere-se ao espaço urbano, no caso de Quarto de Despejo, e teve maior difusão e acolhida nacional e internacional que aquelas duas outras obras. A explicação mais corriqueira para ter sido um best-seller, ou melhor, para o retumbante êxito da obra de Carolina Maria de Jesus, é atribuído à figura exótica que ela representava, ou seja, à exceção que ela simbolizava. Logo, não ocorreu o reconhecimento do valor literário de sua obra e, igualmente, dessa autora, ao passo que escritores brancos como Graciliano Ramos ou Raquel de Queiroz, restringindo-nos a esses dois exemplos, são considerados escritores de fato. Eles podem vir a abordar temas exóticos, porém nunca serão classificados como tal, assim como denominam Carolina e todas as escritoras e os escritores negros.

A falta de reconhecimento da escritora negra e do escritor negro indica o lugar dessas pessoas na literatura que se autoproclama universal 
ou, no máximo, nacional com ambição universalista. Assim, a condição da negra e do negro é a de personagem; diríamos mais, personagens criados pelos brancos. Uma pessoa negra ocupando o lugar de escritora subverte a lógica da classificação social racista (Fonseca, 2003).

O Núcleo História e Memória do Museu AfroBrasil é um espaço cultural que reforça e representa justamente essa subversão. Consequentemente, haverá resistência, sobretudo quanto ao reconhecimento da figura de Carolina de Jesus, por ocupar e representar simbolicamente um lugar de prestígio, o lugar dos letrados. Quando ocorre o reconhecimento em outros espaços, rotulam-na como exótica. Por trás desta exotização de $\mathrm{Ca}-$ rolina Maria de Jesus, não podemos deixar de considerar que ela e sua literatura provocam tensão. Por isso, ela não pode ser tratada de forma indiferente. Carolina é uma pessoa relegada ao papel de personagem que resolveu colocar-se em seu devido lugar, isto é, enquanto sujeito, tornando-se criadora, "brincando de deus". Carolina Maria de Jesus, "reles humana", "simplória criatura terrena", ousou colocar-se no lugar de criadora, e isto não é exótico, é subversivo.

\section{DiáRIO DA FOME}

A obra mais importante de Carolina Maria de Jesus, Quarto de Despejo, foi lançado em ig6o e reeditado oito vezes no mesmo ano. Vendeu em onze meses mais de setenta mil exemplares. Uma tiragem impressionante para época. Nenhum outro escritor brasileiro chegou perto do êxito de vendas de Carolina Maria de Jesus. Nos cinco anos seguintes seu livro foi traduzido para catorze idiomas e alcançou mais de quarenta países.

O livro Quarto de Despejo é um diário escrito por Carolina Maria de Jesus durante uns quinze anos. Ela escrevia cotidianamente suas dificuldades na vida, como a fome que passava junto com os seus dois filhos (Jesus, I993: 52). A autora escrevia poemas, contos, provérbios, pensamentos, pe- 
ças teatrais, memórias e letras de música; considerava os poemas sua melhor expressão artística. Porém, o bom sucesso somente foi alcançado com o diário, publicado com o título de Quarto de Despejo, também conhecido como Diário da Fome. Era realmente um diário da miséria cotidiana, além dos abusos e preconceitos enfrentados por ela, seus filhos e outras pessoas que viviam na favela do Canindé em São Paulo. A narrativa foi escrita de forma caótica, com incorreções ortográficas, sintáticas e de pontuação.

Sem dúvida, a pessoa responsável pela publicação do diário de $\mathrm{Ca}$ rolina foi Audálio Dantas. O jornalista foi até a favela onde Carolina de Jesus residia para fazer uma matéria e, assim, conheceu os seus escritos. O ano era o de 1958 e o diário de Carolina chamou a atenção do jovem repórter alagoano que trabalhava na Folha da Noite. Ele foi autor da primeira matéria sobre Carolina Maria de Jesus e figura fundamental para a publicação de Quarto de Despejo. Ao descobrir a exótica escritora favelada, deu um impulso a sua carreira.

O livro Quarto de Despejo, primeira e única obra de prestígio da autora, critica a vida do pobre residente na favela, caminhando em sentido contrário à "romantização" da favela e do favelado que perdura até os dias atuais e se expressa em músicas como esta:

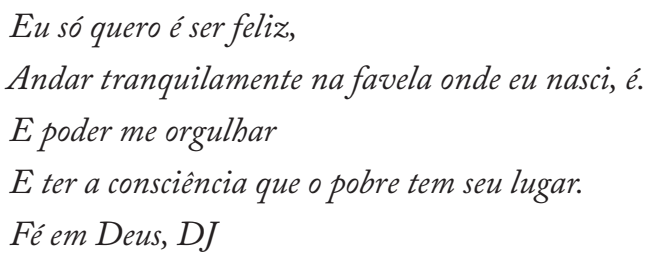

Essa música, composta por Cidinho e Doca em I994 e intitulada Eu só quero é ser feliz, apresenta com propriedade a idéia encontrada em algumas obras artísticas de nossa cultura nacional, que romantizam a pobreza e, particularmente, o favelado. A favela é um espaço de precariedade social em que a maioria das pessoas vive por falta de opção. Entretanto, 
esse espaço aparece expresso em músicas, como essa acima mostrada, a difundir a ideia de que o favelado deve conformar-se e ser feliz com "o seu lugar”, com sua condição de marginalizado. Carolina Maria de Jesus, enquanto cidadã e escritora, simbolizou o contrário disso. Em outras palavras, ela representa a subversão desse lugar destinado ao pobre e especialmente ao negro.

O livro Quarto de Despejo foi publicado nos anos sessenta do século passado. Todavia, esse estereótipo do pobre a que aludimos acima persiste nos dias atuais em produções artísticas criadas pelo próprio pobre. Esse procedimento é o que Karl Marx chama de fruto da ideologia burguesa, isto é, o proletariado (neste caso, o pobre, o favelado) adota o pensamento imposto pela burguesia. Ao agir assim, não ameaça o lugar do burguês, que é o espaço de poder econômico e simbólico (Marx, 2005:827-877).

O favelado fica feliz com o lugar onde nasceu e o burguês mais feliz ainda porque não ocorre um questionamento crítico das desigualdades sociais. Portanto, produções artísticas como essas, por trás de sua aparente inocência, podem ser consideradas produções reacionárias, que não pretendem tensionar, mas, pelo contrário, levar o pobre a conformar-se com a precariedade de sua existência. Porém, não podemos deixar de mencionar que, mesmo na obra de Carolina Maria de Jesus, há certa romantização da favela. Sua obra e figura não deixam de ser paradoxais quanto a esse e a outros temas.

Com o bom sucesso de seu Diário da Fome, Carolina de Jesus pôde finalmente comprar sua casa própria, levando-a a publicar um outro livro, Casa de Alvenaria, em 1961. Essa obra encontrou pouca acolhida e retrata a vida de Carolina desde a assinatura do contrato para a publicação de Quarto de Despejo até a compra de sua casa num bairro de classe média. Nesta obra encontramos os conflitos de uma mulher negra que ascende socialmente. Além desse fracasso editorial, Carolina publicou por conta própria o romance Pedaços da Fome, em 1963 e, depois, Provérbios, publicações que não alcançaram projeção. 


\section{O DRAMA DA POPULAÇÃo DESCARTÁVEL}

Em nossa sociedade moderna, ou pós-moderna, um fenômeno social resultante da aceleração da globalização do capital é o crescimento do desemprego estrutural, de trabalhos informais e do lumpemproletariado (Marx, 2000), ou seja, pobres miserabilizados que não pertencem à economia ativa, não servindo ao capital nem para serem explorados. Melhor dizendo, o lumpemproletariado que Karl Marx mencionou trata-se daquelas pessoas excessivamente dependentes do Estado nacional para sobreviverem. Pessoas em situação de precariedade social, como é o caso da população de rua, os trabalhadores catadores de papel, que muitas vezes ali sobrevivem, a gente da favela, dos cortiços ou das casas de alvenaria precárias, situadas nas periferias urbanas. Esse voltou a ser o caso de Carolina Maria de Jesus, quando vendeu sua casa em bairro de classe média em São Paulo e foi residir no extremo-sul periférico da mesma cidade, em Parelheiros.

O fato de o livro Quarto de Despejo cair no esquecimento resulta do próprio esquecimento dessas populações descartáveis: histórias da mulher, do homem, da criança, do idoso que não servem, nem ao menos, para serem explorados. Ao contrário, representam e significam custo financeiro para o Estado.

\section{ConClusão}

A obra de Carolina Maria de Jesus enquadra-se no perfil dos estudos pós-coloniais, que defendem a tese de que o "subalternizado pode falar por si mesmo". Percebe-se que Carolina, "além de falar por si mesma", produz literatura a partir do seu lugar de enunciação, que é o da opressão, razão que talvez explique o processo de invisibilização que vem sendo aplicado à memória dessa autora na história cultural brasileira. 
Carolina, por existir, por falar, por produzir literatura, acaba por provocar tensão, situação que torna difícil ser indiferente a sua obra e figura.

O Núcleo História e Memória do Museu AfroBrasil, ao visibilizar Carolina Maria de Jesus, coloca de volta a tensão sobre o lugar do negro, considerado como o lugar da precariedade social, o lugar da inferioridade, o lugar da não inteligência, o lugar da pouca inteligência, o lugar da feiúra, o lugar da sexualidade animalesca, o lugar do arcaico, o lugar do selvagem, o lugar do primitivo, o lugar da violência, sobretudo física, o lugar do estupro, o lugar do estuprador de brancas, o lugar da maldição, o lugar do castigo.

\section{Bibliografia}

Araujo, Sonia Maria da Silva. Educação do campo no Brasil: um discurso para além do pós-colonial? In: Revista Latinoamericana de Ciencias Sociales, v. 8, $\mathrm{n}^{\circ}$ I, Enero-Junio, pp. 221-242, 2010.

Bhabha, Homi K. O local da cultura. Belo Horizonte: Editora da UfMG, 2003.

Bonnici, Thomas. Introdução aos estudos das literaturas pós-coloniais. Mimesis, Bauru, v. 19, n. I, p. 07-23, 1998.

Cardoso, Lourenço. O branco "invisivel": um estudo sobre a emergência da branquitude nas pesquisas sobre as relações raciais no Brasil (Periodo: 1957-2007). (Dissertação de mestrado), Faculdade de Economia e Centro de Estudos Sociais da Universidade de Coimbra, 2008.

Cleaver, Eldridge. Alma no Exílio. Rio de Janeiro: Editora Civilização Brasileira, I971.

Costa. Sérgio. Dois Atlânticos: teoria social, anti-racismo, cosmopolitismo. Belo Horizonte: Editora da UFMG, 2006. 
Fanon, Frantz. Peau noire, masques blancs. Paris: Éditions du Seuil, 1952. . Pele negra máscaras brancas. (Trad. Alexandre Pomar), Porto: Edição A. Ferreira, s/d[1952].

Fonseca, Maria Nazareth Soares. Presença da Literatura Brasileira na África de Língua Portuguesa. In: Leão, Ângela Vaz (Org.), Contatos e ressonâncias. Belo Horizonte: Editora PUc Minas, 2003.

Foucault, Michel. Vigiar e punir. São Paulo: Vozes, 2007, $36^{\text {a }}$ ed.

Gilroy, Paul. O Atlântico negro. São Paulo/Rio de Janeiro: Editora 34 e Centro de Estudos Afro-asiáticos da Fundação Cândido Mendes, 2001.

Guimarães, Antonio Sérgio Alfredo. Racismo e Anti-racismo no Brasil. São Paulo: Editora 34. 2005, $2^{\mathrm{a}}$ ed.

HALl, Stuart. Da diáspora: identidades e mediações culturais. In: Liv Sovik (org.), Trad. Adelaine La Guardia Resende et al., Belo Horizonte: Editora UFMG; Brasília: Representação da UNEsco no Brasil, 2003.

Haraway, Donna J. Saberes localizados: a questão da ciência para o feminino o privilégio da perspectiva. Cadernos Pagu, nº 5, pp. 7-4I, I995.

Hasenbalg, Carlos. Discriminação e desigualdades raciais no Brasil (Trad. Patrick Burglin). Belo Horizonte: Editora UfMG; Rio de Janeiro: IUPERJ, 2005, $2^{\mathrm{a}}$ ed.

Jesus, Carolina Maria de. Quarto de despejo: diário de uma favelada. São Paulo: Editora Ática, 1993. . Casa de alvenaria: diário de uma ex-favelada. São Paulo: Livraria Francisco Alves (Editora Paulo de Azevedo Ltda), I96r. - Casa de ladrillo. Buenos Aires: Editora Abraxeas, 1962. . Pedaços da fome. São Paulo: Editor Áquila Ltda, I963. . Provérbios. São Paulo: s/editora. . Diário de Bitita. Rio de Janeiro: Editora Nova Fronteira, I986. 
. Meu estranho diário. São Paulo: Xamã, 1996.

. Antologia pessoal. Rio de Janeiro: Editora Uf RJ, I996.

Marx, Karl. Manifesto do partido comunista. São Paulo: Editora Martin Claret, 2000.

O segredo da acumulação primitiva. In: O capital: critica da economia politica. Livro I. Volume 2. Rio de Janeiro: Civilização Brasileira, 2005, p. 827-877.

SAID, Edward. Orientalismo. Lisboa: Edição Cotovia, 2004.

Sovik, Liv. Por que tenho razão: branquitude, estudos culturais, e a vontade da verdade acadêmica. In: Contemporânea Revista de Comunicação e Cultura Journal of Comunication and Culture. vol. $3, \mathrm{n}^{\mathrm{o}}$ 2, p. I59-I80, julh. Dez, 2005.

SAntos, Boaventura de Sousa. A gramática do tempo: para uma nova cultura política. Para um novo senso comum: a ciência, o direito e a politica na transição paradigmática. vol. 4, Porto: Edições Afrontamento, 2006, p. 259-293.

Spivak, Gayatri Chakravorty. Can the subaltern speak? In: Williams, Patrick \& Chrisman, Laura. Colonial discourse and post-colonial theory. London: Longman, I993, p. 66-III.

Abstract:

KeYwORDs: Colonization; Invisibility; Literature; Misery. 